\title{
Engendering Change within a Water Infrastructure Client Organisation: A Participatory Action Research Approach
}

\author{
Michael Potts ${ }^{1}$, Bankole Awuzie ${ }^{2}$, Peter McDermott ${ }^{3}$, and Andrew Stephenson ${ }^{4}$ \\ ${ }^{1} \mathrm{PhD}$ Candidate, School of the Built Environment, University of Salford. E-mail: m.potts@edu.salford.ac.uk \\ (corresponding author). \\ ${ }^{2}$ Post-Doctoral Scholar, Central University of Technology, Free State, SA. E-mail: obankawuzie@gmail.com \\ ${ }^{3}$ Professor, School of the Built Environment, University of Salford. E-mail: p.mcdermott@salford.ac.uk \\ ${ }^{4}$ Industry Supervisor, UK WASC, Greater Manchester. E-mail: mr_a_stephenson@hotmail.com
}

Project Management

Excellent Paper of EPPM2014 Conference

Received January 8, 2015; received revision May 22, 2015; accepted May 24, 2015

Available online June 16, 2015

\begin{abstract}
Continuing demands by stakeholders for improved service delivery has caused Infrastructure Client Organisations (ICO) in the UK to embark upon organisational restructuring. It is expected that such restructuring would enhance cost-effectiveness and quality in asset management and service delivery. However, this change, if not properly managed and sustained, could result in the inability of the ICO to achieve these targets. This study outlines the use of systemic thinking and Participatory Action Research (PAR) in driving and managing such change within a UK-based Water and Wastewater ICO (UK WASC). Besides highlighting the context for change in response to policy, austerity and regulatory pressures, this study portrays how the PAR approach can assist in the management of change within ICOs. Furthermore, it provides an insight into the evolution of an external researcher, from novice to expert within the ICO, imbued with the required knowledge to encourage other stakeholders to participate in driving the change management process. Preliminary findings indicate the usefulness of this phased approach toward PAR. This study provides a platform for researchers wishing to engage with ICOs to improve service delivery, identifying the value of engagement, change and systemic thinking.
\end{abstract}

Keywords: Infrastructure delivery, participatory action research, change management.

\section{Introduction}

Issues concerning poor quality infrastructure and the delivery of infrastructure-related services have continued to elicit high levels of interest in recent times (HM Treasury, 2010). Successive governments have sought to devise strategies that ensure investments in the provision of infrastructure achieve optimum benefits for both society and the economy. Regulation, deregulation and unbundling of service provisions are among a plethora of mechanisms through which governments aim to achieve value for money amongst other favourable benefits associated with the delivery of infrastructure services (Alexander and Estache, 2000; Kessides, 2005; Eberhard, 2007).

However, criticisms continue to trail these Infrastructure Client Organisations (ICOs), especially with regard to poor cost effectiveness and service delivery despite the introduction of these mechanisms (IUK, 2012). Helm (2013) highlights that British infrastructure is a source of almost constant study and criticism, resulting in a host of demands in water, energy, transport and communications represented by National Infrastructure
Plan (NIP) Statements, made by the coalition government in light of industry reforms resulting from the October publication of the NIP 2010 (HM Treasury, 2010).

In the UK, these criticisms have led to a shift in focus towards the resilience, value, investment in and efficiency of infrastructure assets coupled with their procurement, delivery and management (IUK, 2012). ICOs in the UK are being tasked to streamline their internal and external processes towards efficient and effective procurement, delivery and management of critical infrastructure assets and services to the final consumer (IUK, 2013). Undoubtedly, streamlining the internal and external processes within these ICOs would bring about change. Achieving such change can pose a herculean task, and often, introducing enduring change into such organisations requires the collaborative resolve of all stakeholders involved. One of these such ICOs in the UK (UKWASC) has shown to be striving to achieve both regulatory and organisational service delivery targets, and subsequently commissioned a study to review its internal and external delivery processes with a view to engendering lasting change. It is expected that this study would identify 
barriers to efficiency and introduce change processes to influence and enhance optimised service delivery.

To enact such change has required the formation of a phased change approach to gain maximum impact from the levels of resources available to the project. This paper therefore seeks to highlight the significant value of the approach applied to this project. Whilst the capability of the Participatory Action Research (PAR) approach in facilitating enduring and sustainable change has been buttressed elsewhere (Whyte, 1991; Rahman, 1993), there appears to be a paucity of studies detailing the evolution of the researcher from an external party to the organisation and it's processes, to an involved practitioner able to drive change and encourage participation of various stakeholders. This evolution is what this paper seeks to identify and has been summarised as the Three Phase Change Approach (TPCA), which sees a transition from using Participant Observation (PO), to Action Research (AR) and onto PAR.

\section{Infrastructure Investment and Delivery: Issues Arising}

As far back as Smith (1776), the topic of infrastructure spend to encourage economic growth has been a focus for policy. Notably, 'there is an obvious and important policy implication (from the 'Aschauer Hypothesis'): that governments can increase real output and productivity substantially by stepping up infrastructure investment' (Ford and Poret, 1991). Although more recent reports (Egert et al., 2009; Crafts, 2009) point towards the positive impact of infrastructure investment on GDP growth, Gramlich (1994) draws attention to the need to understand appropriate levels of infrastructure requirement, whilst consideration is required in understanding the relative benefits of that investment (Tao et al., 2011). Infrastructure investment and its resilience (Bissell, 2010) and the future challenges to the economy, industry and national prosperity are also important (Ofwat, 2013). This has led to a two pronged discussion around infrastructure, namely, the requirement to invest in infrastructure to facilitate growth, and the efficient delivery of that infrastructure to gain best value (HM Treasury, 2010, 2013).

The divestiture of the water sector in England \& Wales, resulting in private regulated regional monopolies, can be seen as an example of this drive to create efficient delivery, while issues with monopolistic infrastructure delivery pertain to vertical integration, bilateral monopolies, and a lack of competition and monopolymonopsony relationships (Hillebrandt, 1985). Within this type of delivery arrangement, there is an assumption which indicates that the need to drive value and competitiveness does not exist. The water sector and its typically long term relationships and high fixed investment costs (Akintoye and Renukappa, 2013) should therefore become subject to assessment of its delivery of relational contracting and the effectiveness of their delivery systems. Buoyed by the construction industry's prevalence towards a 'systematic approach' to delivery (Mazet and Portier, 2010), creating an industry of specialists, there is a need to focus on the 'systemic' delivery of services to drive out inefficiencies and create value. The high costs associated with the delivery of infrastructure services have been traced to stop-start investment programmes, lack of clarity and direction, poor budget management, over-specification, in-effective use of competition, poor strategic use of supply chains, and a lack of investment in skills (HM Gov., 2011) resulting in the UK having the fifth highest civil engineering costs in Europe (HM Treasury, 2010).

\subsection{The State of Infrastructure in the UK Water Sector}

Within the UK context, the sector's focus on resilience, value, investment and efficiency is evident in Infrastructure UK (IUK, 2012) and the Industrial Strategy (HM Gov., 2013) both of which build on principles within the National Infrastructure Plan (IUK, 2011). The focus here is on the maximization of investment below the optimum level discussed by Barro (1990), and with the financial crash and resultant downturn in GDP (OECD, 2013), policy makers have focused their attention towards issues such as stability, value, client skills, efficiency, cost benchmarking and growth (Cabinet Office, 2011).

Despite an increase in annual infrastructure investment in the UK from the $£ 41$ billion annual average between 2005 and 2010 to its present level of $£ 45$ billion per annum (IUK, 2013), EC Harris (2013) lists the UK as being 'asset rich' and relatively 'cash poor'. The World Economic Forum (2012) lists the UK as $24^{\text {th }}$ in terms of overall infrastructure quality, while the Treasury (2013) and Infrastructure UK (2013), refer to ageing assets and inefficient delivery of projects as the main stumbling blocks in UK infrastructure. Efficiency and maximizing appropriate value from infrastructure investment is the key to sustaining a strong economy, to this end, focus is given to critical, asset rich, but efficiency poor infrastructure providers such as the privatised water sector in England \& Wales (HM Gov., 2013).

Private water and waste water companies regulated by Ofwat (The Water Services Regulation Authority) can see this value focus on efficiency, as recently as January 2013 and the 'Setting price controls for 2015-2020 framework and approach' issued by Ofwat focusing on delivery, securing value for money, using water resources better; evaluating and mitigating risk, and assessing historic performance. With an ageing infrastructure asset base and forecast population growth, the water sector is under considerable scrutiny with regard to its effectiveness in delivering value, driving innovation and their preparedness for the growth in demand (Akintoye and Renukappa, 2013).

\section{Change within UK WASC}

The management of change is an important process which assists an organisations' transition to a desired future state. It can focus on a number of levels, from the individual, to the team or the whole organisation (Kotter, 2011). Balogun and Hope Hailey (2004) assert that seventy percent of change management programmes fail. Todnem (2005) traces this failure to the likely 'lack of a valid framework of how to implement and manage organisational change'. This project seeks to address the gap in knowledge around the improvement of the delivery of infrastructure within a regulated environment, specifically within a water industry ICO. 
The research proposition is to address the institutional gap in knowledge with regard to the delivery of infrastructure assets within the UK context through a single institutional arrangement, such as with a regional monopolistic Water and Sewerage Company (UKWASC). The result will be the creation of a new Infrastructure Delivery System (IDS) within UKWASC to which this project will have assisted in formulating change.

This project has been structured around the TPCA, utilising a $\mathrm{PhD}$ programme as a driver (among other initiatives) for change. The project focuses on a core compliment of intervention within the organisation to facilitate the data gathering for the system itself. Building on Lewin's Unfreeze, Move and Re-freeze (Lewin, 1951), this project is aligned to a 3+ year relationship with the ICO involving an embedding of the researcher within UKWASC, data gathering, changing and testing, and finally, adapting and finalising the changes. Burnes (2004) highlights that organisational change theory exists across three perspectives (levels), namely the organisation, the group and the individual. An important issue and consideration is the prevalence of professional groups typically found with an ICO and the need to understand the nature (and process) of professionalization (Abbott, 1988). Understanding and enacting change amongst these distinct professions abutting one another within an ICO is an important aspect of the engagement process as coupled with a consideration of multiple perspectives.

The study involves a number of interventions aimed at improving service delivery and bringing about real world change within the focus ICO. The identification of the interventions and their relative position (perspective) and focus (working groups) is through the Change Management Protocol (CMP). This acts as a bridge between the theoretical foundations for the project in Strategic Procurement Management and Systems Thinking and the practicalities of action within the ICO. Whilst not fully detailed here as to not distract from the practical implications of the TPCA, the CMP is an important research gateway between theory and action and is discussed within Section 5. A helpful way of understanding this tool is to consider a contribution to theory on one side, and a contribution to practice on the other, the result, real world change and a better understanding of infrastructure delivery within a UKbased ICO.

When defining interventions in the context of change management, it is important to not only consider the nature of the change and its position, but also the typology of interventions in the given scenario. Huse and Cummings (1985), originating from Lewin's Open Systems Theory (1947), propose a model for organisational 'diagnosis' based on the three perspectives highlighted by Burnes. Interventions into these 'levels' come in four forms: (1) people and organisational processes, (2) technology and organisational structures, (3) human resource systems, and (4) strategy and environment. Open systems looks at organisations as a series of interconnected sub-systems, whereby change in one area will affect change in another (Scott, 1987). Thus, change must be viewed as a holistic whole, not in departmental isolation if it is to be effective. Miller (1967), in connection to open systems, breaks the organisation into four sub-systems, namely (1) the organisational goals and values sub-system, (2) the technical sub-system, (3) the psychosocial sub-system, and (4) the managerial sub-system. The psychosocial subsystem may be better known as the organisational culture and/or climate. Making clear the framework within which one is structuring an intervention is thus vital in setting expectations and understanding the nature of change through the focus ICO.

Considering the interplay between intervention types becomes ever more important when, such as at the outset of this project, where an extensive business change and procurement process was underway within UK WASC. This process was in accordance with their quinquennial price review period, aligning to the relative Asset Management Plan (AMP) periods, the forthcoming AMP6 being from 2015-2020. The value of immediate change and the creation of self-help competencies (Shani and Pashmore, 1985) was thusly seen as an invaluable process. This caused the creation of an Action Research Framework (ARF) (McNiff and Whitehead, 2009) with a three phased approach aligned to Lewin (1951). However, considering the emergent approach to change, the development of the researcher within the focus ICO, the development of organisational acceptance of the approach, and the need to ensure active participation of stakeholders, the approach is better described as the Three Phase Change Approach (TPCA). The TPCA is split into Unfreeze, concerned with PO, among other methods. Move which utilises AR and Re-freeze which begins to focus on PAR.

\subsection{PAR - An Appropriate Approach for Change Management?}

PAR has been defined as a research approach wherein persons from within the organisation actively participate with the professional researcher throughout the research process (Whyte, 1991). Similarly, whilst appraising the strength of PAR, Argyris and Schon (1974) observe that the approach offers a more practicable platform to enable researchers to achieve both rigour and relevance when carrying out a research project, a constraint which had appeared insurmountable in the past for social science researchers. The decision to adopt the PAR approach was premised on achieving sustainable change within UK WASC via collaboration with the various stakeholders identified as being responsible for the organisation's internal change processes.

As a result, it was vital that stakeholders participated in the identification of the problem, data collection and reflection in collaboration with the researcher. This active participation in the research process has since been identified as a salient advantage of the PAR approach (Rahman, 1993). It leads to the development of workable change model(s) based on group consensus, as well as the promotion of continual improvement and if need be, (re)invention of the developed model(s) long after the culmination of the research project. It is however highlighted here, that a transition period is required to enable an effective PAR process when initiating change (or research) as an external party, and that in fact, the coupling of PAR with other methods can be a somewhat more effective approach, especially with regard to the overcoming of 'barriers'. 


\section{Research Methodology}

In this study, a qualitative single case strategy was applied within the focus ICO. Although there continues to be concerns about the validity of single case study findings, Yin (2009) insists that the choice of whether to adopt a single or multiple case study strategy is dependent on the purpose and nature of the research. It is maintained that single case studies are especially advisable where the case is either unique, critical or an exploratory one. In this study, the case satisfies these three tenets.

It is noted however, that a development of the study could be in the form of further engagement with other UK-based ICOs in the creation of new IDS(s), but such an engagement within the timeframe of this project would have been to the detriment of the process and against the principles and value of the TPCA. Exposure to sensitive processes and information through interventions, as well as the building of relationships through the embedding process is vital to the enacting of extensive change. It is considered vital to the TPCA and is thusly inextricably linked to a single focus situation and the creation of an ideographic contribution to theory and knowledge through action.

In similar studies, it has been shown that the collection of data has involved a great degree of spontaneity (Hartley, 2004), and is usually of a qualitative nature. This made the adoption of PO, unstructured and semi-structured face-to-face interviews and workshop sessions, a natural route for data collection from a research perspective. As with most cases involving participatory focused research, the process of initiation always poses a challenge to the researcher. Whether initiated by the client or researcher, the entry paradigm differs, such as with guaranteed organisational entry with client initiated research, but this can be counterbalanced by a drive to focus on client derived issues (Schein, 1999). It is important then to define the social and psychological contract that will govern the relationship, and thus make clear its foundation and focus.

To this end, a project evaluation model is proposed in Table 1. For this project, the initial originator of this project is the research body, in collaboration with UK WASC, with a view to the development of a $\mathrm{PhD}$ programme within the research body. With this, the level of organisational entry is high; however, the focus is loosely prescribed and the skill level of the researcher is expected to develop in stages. The results are concerned with the parameters set in collaboration between researcher and organisation, utilising high client involvement.

Schein (2008) observes that researcher initiation of a 'project' where the researcher and client involvement is high, usually results in AR. When linked in conjunction with the development of a $\mathrm{PhD}$ programme, the associated change in researcher skill level requires the division of the research process into phases, and as such aligns with the Three Step Change model of Kurt Lewin (1951). This is not to say that the consideration of 'change readiness and facilitating for change' (Todnem, 2005) of the emergent approach is not considered, especially with regard to the changing internal and external pressures of a contingent approach to change strategies (Fawcett et al., 2008). But that, although the three step model may be criticised for its small scale nature, its application is being used in a macro 'structural' sense, whereby interactions are relatively small scale, but the implications have wider connotations. Thus the overall structure of the change approach is in three phases, with contingent strategies within it that correspond to a changing research narrative to suit the developmental nature of the project and the focus environment.

\subsection{The PAR Approach to Fostering Sustainable Change}

Considering a multitude of factors, from understanding the focus of organisational issues, researcher development and project definition to participatory learning through an iterative cycle. The TPCA is split according to three constituent research phases, each representing a differing psychological contract with the focus ICO.

The inclusion of the psychological contract may not seem particularly pertinent at first glance, as typically, this is in reference to employee to employer relationships. This contract however, characteristically determines the extent to which an employment relationship is defined in terms of mutual obligations or expectations (Rees and French, 2013). Rousseau (1995) offers a useful typology of this relationship, using timeframe and performance requirements as dimensions, representing a form of continuum between short term variants of transactional and transitional relationships, to longer term arrangements of balanced and relational.

This differing vantage point serves as a baseline from which to understand the 'implementer' (this case researcher) and organisational relationship. Especially in the case of a large organisation such as an ICO whereby the creation of 'working' psychological contracts could be perceived as the underlying norm (Argyris, 1960). Thus an understanding of the project's relationship with the normative working environment is pivotal in positioning the manner in which the project is to be carried out. Long term unspecified 'contracts' lead to high levels of commitment and stability for example in the relational form. While short-term specified situations lead to low levels of commitment and high turnover (exit) rates in the transactional form, as well as 'little learning', a form more akin to consultancy in this regard.

Table 1. Project initiation

\begin{tabular}{cccccc}
\hline Originator & Entry & Focus & Skill Level Expectations & Results Expectations & Client Involvement \\
\hline Client & Specific & Predefined Issues & Medium & Practical and directive & Medium \\
Research Body & High & As Unearthed & Low - High & Unexpected & Low - High \\
Consultant & Low & Within Skill-set & High & Specific to Topic & Low \\
\hline
\end{tabular}




\subsection{The Three Phase Change Approach}

The three phases of the TPCA begin firstly with PO. PO is in essence a data collection method, whereby immersion of the researcher into the setting allows the researcher to gain a rich understanding of the factors affecting those being studied (DeWalt and DeWalt, 2010). By 'putting you where the action is' (Bernard, 2011) PO acts as one of several methods within the qualitative research framework, whereby the goal is to understand the nature of the phenomena opposed to quantification of it. Multiple sources are used from informal interviews, pure observation, a review of policy and literature, document reviews and the building of social networks within the organisation.

Gorman and Clayton (1997) identify four main qualitative research approaches as observation, interviewing, historical research and group discussion. All of which are utilised in this approach. It is important that a social contract is created here by which the practitioners understand the aims of the project and its foundations (Mackenzie et al., 2012), collaboratively and sensitively defining the project expectations in the process (Denscombe, 2010).

A moderate participation role (Spradley, 1980) is taken in order to differentiate between researcher and practitioner, whereby $\mathrm{PO}$ in this manner allows appropriate involvement and a relevant amount of detachment to remain objective (DeWalt and DeWalt, 2010). A primary aim with Phase 1 of the research is to define the baseline from which the AR effectiveness can be judged (McNiff and Whitehead, 2009) and future organisational engagement can be addressed (Mackenzie et al., 2012).

As the researcher becomes more skilled and further aligned with the processes and forces affecting the focus organisation, collaborative working strategies with participants begin to form and an effective 'observation into action' barrier is crossed. This leads to the use of AR and the beginning of Phase 2. AR is a self-reflective process aimed at improving practice, going beyond the extent of external review and strategic theory building, but keeping full integration at arm's length. Again, multiple methods are used, from semi-structured interviews, surveys, workshops, discussion groups and further policy and literature reviews as action strategies are developed with co-researchers.

Shani and Pashmore (1985) summarize the situation as 'it (AR) is simultaneously concerned with bringing about change in organizations, in developing self-help competencies in organisational members and adding to scientific knowledge'. AR and the 'Action Reflection Cycle' (ARC) of McNiff and Whitehead (2009), follows a process of 'Observe, Reflect, Act, Evaluate, Modify, Move in new directions'. This cycle, which is selfperpetuating in nature, suits the enacting of organisational change within a project or programme culture. With this, AR becomes 'Research in action, rather than research about action' (Coghlan and Brannick, 2005), so takes a pro-active role within an organisation. It therefore takes on a human role within the organisation as the researcher becomes an active member of the process. A key point is the responsibility on the researcher to 'enact' change. This imparts a component of direction, such that the researcher dictates the extent to which the result will be defined.

Following a series of ARC's, the researcher gathers knowledge and generates a set of skills comparable to that of their peers. As the researcher and peer group begin to focus on 'I/we' and 'our practice', the research process moves beyond the PO focus on 'they', and the directive 'we' of AR to become a collective 'I/we' of PAR. This then constitutes Phase 3. Ottoson (2003) connects the holistic 'quantum' paradigm of PAR with self-reflection and managerial / organisational change, utilising participation or involvement as a key differentiator of the method from Newtonian classical approaches. PAR is focused on the improving of group / organisational practice wherein the process itself forms an appropriate basis for effective change within the given scenario (Whyte, 1991). Here the focus is on enacting real world organisational learning to better understand the complexities of the organisational issues (Ottosson, 2003; Mackenzie et al., 2012).

This leads to an ongoing reflective process where actions have become the ownership of the individual and the ICO, and 'spin-off' groups / actions and changed processes replace the directive focus of AR. It is important during this stage to take stock of the resultant knowledge change within the organisation and the formation of new behaviours (Burnes, 1996). Here, the data gathered during the AR/PAR cycles will be viewed in relation to the initial baseline defined by PO. It will be instrumental in seeing the effectiveness of diffusion (Hall and Mairesse, 2006) within the ICO to provide feedback into the organisation about how to reflectively enact the process again. Here, artefacts such as Action Research Reports will become important reflective documents for the ICO. During Phase 3, it is important to act and reflect simultaneously, identifying one's own practice and reflecting on next steps (Kindon et al., 2007).

It is important to note that this structure shares some comparisons with the Soft Systems Methodology (SSM) of Checkland (1989) and lends heavily to interpretive systems thinking (Daellenbach, 2001). A key difference with the TPCA structure, is the creation of what can best be described as the '8th step' (see Table 2), which encompasses 'finding and changing', and PAR thus includes practice, off-shoots in action and the 'refreezing' of change into commonality.

Contingency theory plays an important part in this change, whereby moving away from the no-one best way paradigm of polar opposites towards a more situation specific approach is considered. This places the specifics of the situation at the forefront of the decision making process (Woodward, 1965). While restricted by the internal and external forces via the planned approach, managers utilising an emergent / contingent view are free to determine the extent to which factors exist or play a part on the key elements of technology, size and environment (Burnes, 1996). This ability to modify parameters led to the focus of change within a planned 'structure', but with a focus on emergent principles. Such that change, and change management is coherent, with the initial focus issues being targeted, but with the aim of 
76 Potts, M., Awuzie, B., McDermott, P., and Stephenson, A.

facilitating 'change' skills and creating 'changing' knowledge pathways opposed to creating a desired future state. The TPCA is thus aligned to the 5 stage ICO internal re-procurement change process within the UK WASC (see Fig. 1 below).

Table 2. The TPCA in comparison

\begin{tabular}{ccccc}
\hline & $\begin{array}{c}\text { Soft Systems } \\
\text { Methodology }\end{array}$ & $\begin{array}{c}\text { Action Reflection } \\
\text { Cycle }\end{array}$ & 3 Step Model & TPCA \\
\hline 1 & $\begin{array}{c}\text { Entering the situation } \\
\text { Expressing the } \\
\text { situation } \\
\text { Formulating root } \\
\text { definitions }\end{array}$ & Enter organisation & Unfreeze & \\
3 & Building Conceptual \\
Models & Reflect & & \\
4 & Comparing the & Act & AR \\
5 & Defining changes & Evaluate & & \\
6 & Taking action & Modify & & \\
7 & Move in new & & PAR \\
\hline
\end{tabular}

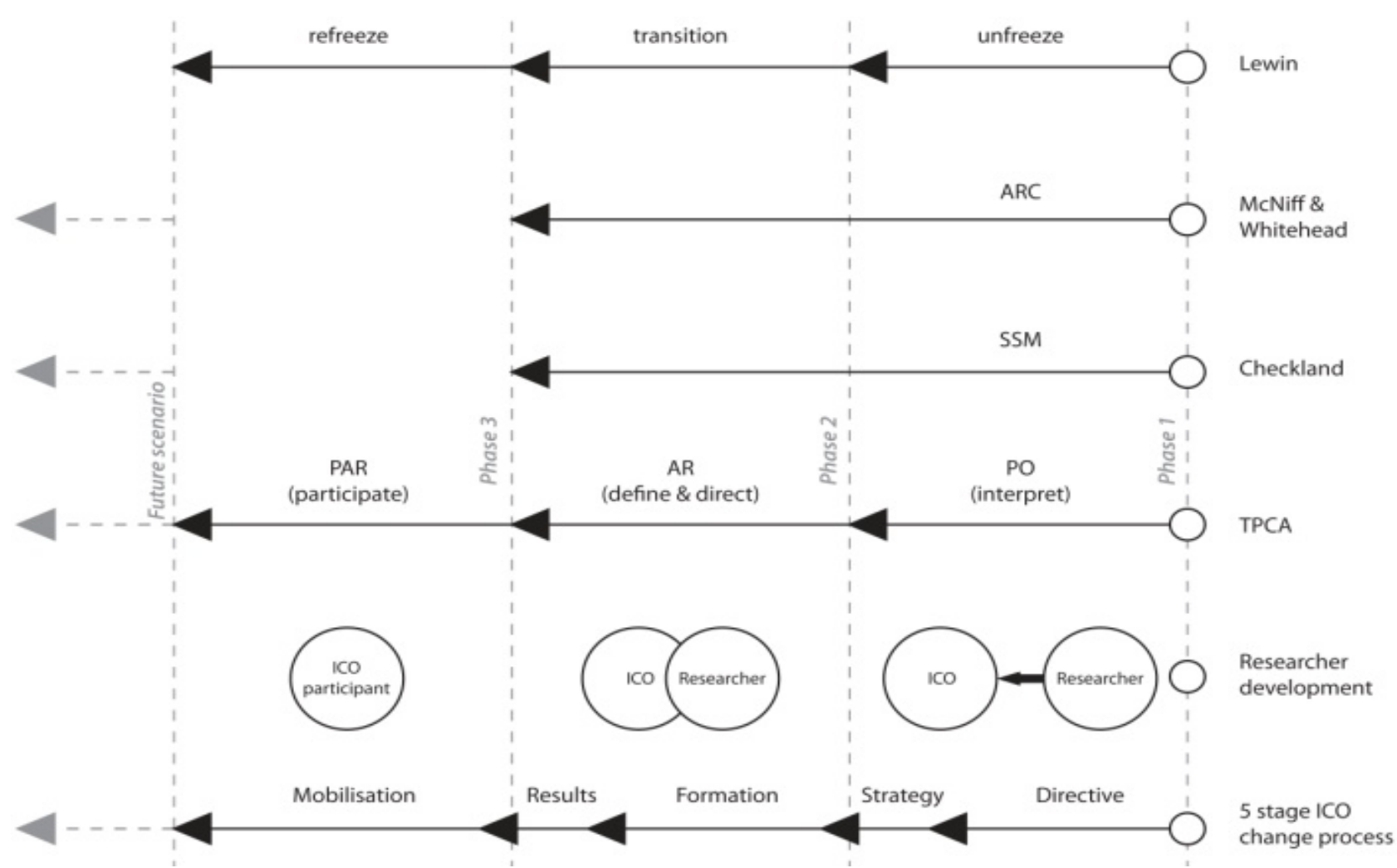

Fig. 1. The TPCA structure in comparison 


\section{Findings and Discussion}

As a method, the TPCA demands a high level of commitment, from both researcher and organisation. Change does not naturally sit well with everybody, and little credence is often given to 'outsiders' to change processes. This evolution from outsider to insider is the core tenet of the TPCA. The process cannot be thrown to one side as a consultants whimsy to suit the bias' and demands of a task master, but instead is as much the responsibility of the organisation as it is the researcher who primarily enacts it. In accordance with the 5 stage ICO internal re-procurement change process, the following outlines the value of the TPCA:

\subsection{Directive}

The project is initiated and the respective roles of participants are made clear. Initial focus on intervention areas remains unclear while the researcher (implementer) is immersed into the focus environment. It is important to limit the focus scope to a manageable level at this point, hence making project drivers clear throughout the research is vital. Without clear limits, it is easy to blur the lines of roles, responsibilities and impact, which could be irreparable from an overall perspective. Remaining flexible is still important, such that moving boundaries is acceptable, almost inevitable, and certainly encouraged, but be clear as to where they are, and make sure all concerned see them the same way.

The next step is to gather information on the focus situation, making clear any assumptions and external influences. This will begin to create a model of the situation, the pressures, issues and a supporting definition of a wider issue of concern. This begins to answer the 'what are you here for' question.

\subsection{Strategy}

An amalgam between research focus areas and a reflection on theory should now commence. This is where the step into praxis begins. The focus areas remain ostensibly large at this point, but the definition of the project can take place. There is a synthesis between literature and the ICO to find a valuable, effective and usable medium between wider systemic focus, internal politics and availability of resources (primarily).

Coming toward the end of the stage, the understanding of the project drivers are more clearly known by the ICO participants and they can push back on the final areas of focus. This creates a tiered level of 'buyin' from stakeholders, those with little interest, and those that either (1) want the result, (2) want a result and the knowledge of how, and (3) those that want to co-design the process and be a part of the result. Understanding the needs of participants during this stage is important; while the output from the Directive stage will form areas of concern, focus and value, an important step is to define where the researcher and the ICO interact more specifically.

A helpful way of doing this was found to be through the formation and use of a Change Management Protocol (CMP) which contains a series of 'strands' or 'themes' identified from the Strategic Procurement literature. Each strand is identified within the focus situation and an intervention strategy formed that addresses each strand in response to a systems view of change, whereby change in 'one area' can be ultimately unsuccessful if not complimented by change within connected areas. This view of holism, with consideration given to sub-wholes, or systems within systems is the basic nature of this approach.

What can then be done is to relate certain areas of concern within the ICO to the strands as described by the CMP with key ICO participants, effectively creating a series of options. This relationship between project strands and issues of concern can synthesis the project and form a series of focus areas, areas that inevitably form the basis of interventions. Simply put, strand A includes potential topics B, C and D, the organisational areas of concern $\mathrm{E}, \mathrm{F}$ and $\mathrm{G}$ then relate to topic $\mathrm{B}$, but there may only be time and access to F, and so forth.

Discussions can then take place that define where best to place interventions within the ICO in relation to the theoretical lens used by the researcher. This in turn sets limitations and a communicable strategy within the ICO, such that the researcher (A), is working in department B in conjunction with participants $\mathrm{C}, \mathrm{D}, \mathrm{E}$ and $\mathrm{F}$ for the timeframe G. This is essential in setting psychological contracts between the researcher and ICO participants, because at certain levels, the researcher will be heavily involved and understanding of one-another's drivers will almost become intrinsically linked to becoming effective. In other situations, the relationship may be more tenuous, arm's length or even somewhat mechanistic.

This bridge between theory and action is vital in creating a valuable contribution to knowledge. This splits action from theoretical focus, but still maintains an element of value to the focus ICO. What a researcher must consider is the creation of a mental model of the situation at hand (Kutsche, 1998) resulting from the PO phase. It is this model that is brought forward into the CMP such that the researcher entering the CMP has two hands full, one with literature and a theoretical framework, the other with a model of the organizational issues resulting from PO. It is important to consider this process appropriately in order to contribute back to theory effectively through intervention, but to maintain a level of value and importance to the organization that they can dictate and own. This is a key difference between using the TPCA for research and using a TPCA type framework in a consultant approach.

\subsection{Formation}

The key participants are both emotionally and resourcefully bought into the process and areas of focus are clear. The next step is to design the range of interventions collaboratively, ironing out stakeholder engagement issues and tying together with other relevant ICO processes. Interventions at this stage may very well become of more interest to the disengaged. 'Design' is intentionally left vague, and there is an important reason why. For certain participants, they may have tools and techniques to reach decisions that are made explicit, such as with Six Sigma or Lean professionals. Others may 
have personal skills that are more implicit, such as the problem solving skills of an engineer.

Whatever the group make up and skill set, it is important that the researcher is open to all avenues, which may put extensive pressure on the researcher to learn skills to suit, possibly outside of their comfort zone. The key area of somewhat inflexibility is the extent of the project (and topic) boundaries. As the researcher may now be in a subset of the overall project, knowing what is required, when, how and what for can almost become a constant process. 30 minute meetings can easily tie a participant into ten 2-day workshops, but are these vital to the project 'as agreed'? Again, flexibility is important, but rigidity (or rigour in this instance) is where research must relate to stay separated from consultancy.

It is then important to begin the interventions, being careful and open enough to either abandon a route of enquiry, or re-assess assumptions to suit the changing ICO environment. Should the ICO realise two weeks into a four month intervention that this group is to look at something else, that does not immediately mean the researcher is to follow. The course of action for research was formed during the Strategy stage and thus should remain connected. The ICO may wish for the researcher to 'move' with the changes, especially as they become more connected with individuals, but it is important that both the organisational liaisons and the researcher reiterate the project aims. 'Moving away' requires connection with the initial Directive stage, and thus if the move does not link, the intervention is over.

During this stage, the co-creation of objectives may lead to unknown outputs born out of collective and collaborative learning, requiring reflection on initial change parameters. The participants may create something unexpected or as planned in accordance with their initial intentions, but the initial drivers should still align, such that 'we intended to solve $X$ by making Y....we ended up with $\mathrm{Z}$ instead, but its far exceeded what we thought'. Conversely the negative could be true, but being aware of the 'blockers' and making them explicit throughout the process is important.

\subsection{Results}

Here, the outputs of any intervention are communal. The researcher becomes a developed participant and the value of the process may become more valuable to others. The value at this stage is engagement, progression and the developmental knowledge of the fellow participants. The researchers' role is now to facilitate the embedding of these results into practice and day to day working. This requires a focus on 'what's next and how could we be better'?

The researcher should now be viewed as an instigator of the programme at hand. The trust and focus on 'ours' and 'mine' is where the interventions and changes now spiral out beyond the design of a research intervention, with organisational participants taking their respective learning and affecting their day to day lives. This is where the extensive, and even repetitive nature of making explicit the project drivers during the previous three stages pays dividend.
Without this constant process of reflection, the researcher may find it difficult to pinpoint what eventual outcomes are as a result of the researchers' actual impact. Attendance is not an appropriate back story in this instance, merely taking part represents no proof of real impact at all. The proof, and importantly, the reflective impact on real world practice and change, comes from the ability to, without question, make manifest the decisions, actions and approaches that led to a particular outcome.

It is paramount that the researcher and their fellow participants understand what went wrong, what was wasteful and what could be improved. It is very easy to be proud of a result, or at least reflect with rose-tinted glasses in some fashion. The value comes from real, somewhat more difficult reflection on actual events, but this will help future working practice as intervention outputs affect wider business outcomes.

\subsection{Mobilisation}

Here, the focus is on enactment and the value of day-today working. Processes and practices focused on 'moving' from one state to another have been replaced with the performing of 'new working'. The focus is now on the study's work, and how the research interacts with fellow employees. This may require clarification of the intent of the researcher around the initial reasons for the focus.

In some instances, actions may have led to 'let's do this again' or 'can we change the group next time'? As the reflection now becomes about what one is doing, rather than how it was achieved, the previous stages of reflection and interpersonal analysis are central to the avoidance of organisational sleepwalking to a new state, unsure of what its purpose and value is besides 'this is what we now do'. An important question here, for the researcher primarily, is to return to the questions aired during the Directive stage, such as 'what are you here for'? These may have seemed undiscerning at the time, but they serve a significant purpose in that, it could be very easy to merely placate such adverse attitudes, but that would send interventions on an irrevocable tangent in opposition to the actual research aims. Such action, would lead to the undermining of the Mobilisation phase due to such pacification focused activities being contrary to the theoretical framework of the research actions, especially with respect to the Directive stages and early observations.

Now, as the researcher is seen more as a co-worker, a member of the team driving towards a result (of some kind), the issue of 'close-down' becomes crucial. At the Strategy stage, this defined point may have been hard to identify without specific timeframes for example. But then such finite time periods could run contrary to actual business processes. This then naturally leads to flexibility, but flexibility can easily lead to uncertainty.

A way to combat this was found, again through repetition of the researcher's aims and objectives requiring consideration of timeframes at the Directive and Strategy stages, but also on what constitutes 'completion' of an intervention. Did you intend to make something and it was not made; did you intend to already be doing something else but started doing that weeks ago and the team has moved on? Many permutations can influence project closure, possibly none more so than the transfer of 
actions, or responsibilities that have become manifest within the researcher's wider remit. This is where the alignment of outputs and outcomes to the researcher's initial goals plays a part, such that divergence from the initial framework has not occurred or at least inconceivably too far.

So while researcher participation and development requires a vast amount of management to simply remain on track, this is what separates the researcher from the consultant, especially with regard to the creation of focus and maintaining those goals in light of alternative organisational pressures. Of course, considering an organisation in transition is essential, such that goals and drivers may change, but again, aligning to the initial goals and their relevance (over longer time periods at least) is an integral component to this approach.

\section{Conclusion}

The TPCA has proved to be an effective process for managing change in a number of ways. In Phase 1 , this is by using objectivity and externalisation as reasoning behind identification of elements to focus on. One then forms change strategies collaboratively utilising a particular theoretical lens. In Phase 2, it takes the organisation 'on the journey' to redefining strategies in relation to those issues. In Phase 3, those strategies become as much the responsibility of the researcher as they do anyone else. This transition from external to internal, from identification to enactment is a core tenet of the TPCA.

The TPCA has helped to identify preliminary findings, such as the usefulness of the PO, AR and PAR phased approach in topic identification in relation to theoretical constructs and 'actual' organisational issues. The TPCA approach has unearthed issues such as the duplication of resource, internal power structures as inhibitors and the need to change behaviours to overcome internal organisational silos as areas requiring change and subsequent management. The study provides a platform for engaging with ICOs to improve service delivery. It identifies the value of engagement, change and systemic thinking as well as a process for use beyond the focus context.

Creating an amalgam between researcher, reflection, identification, objectivity and practice is what adds value to the engagement process. The researcher of course brings unique biases to the process that need to be espoused and made clear to those involved. But the push and pull of the process with the focus organisation, effectively through co-creation, allows for the removal of my or their view to create our view. This move to the creation of 'our view' is where the TPCA creates unique, collaborative and valuable change in the real world.

The TPCA amalgams three research standpoints into one process, but requires a lot of personal investment, from both the implementer (in this case researcher) to the organisational liaison(s) (who must act as scope/focus filter between implementer and organisation). There are numerous pitfalls that would hamper the enactment of the process in any other order, such as PAR when not familiar, or PO when already a part of working processes. The effective 'buy-in' via differing manners to suit the three phase approach that identifies, strategizes and implements change is an important reflection. No single strategy at day one of a change process can truly predict the outcome, to expect as much, creates misalignment or inappropriate strategies for change. To plan a structure, within which contingent change strategies and actions will take place is the value of the TPCA.

In effect, this process creates change agents, focused on the betterment of their own practice to aid in their own working lives, to tackle either tangible or more underlying issues hampering their organisational development. This study offers an alternative approach to the delivery of service improvements from within an ICO, besides identifying the nature of intervention in a collaborative and innovative manner to drive and manage internal change.

\section{Acknowledgements}

This project is being facilitated through the application of an Industrial Cooperative Award in Science \& Technology (iCase) PhD Studentship via the Engineering and Physical Sciences Research Council (EPSRC). The authors would like to thank UK WASC for not only their participation in this research, but their active role and the levels of access and cooperation provided.

\section{References}

Abbott, Andrew. (1988). The system of professions: an essay on the division of expert labor. Chicago: University of Chicago Press.

Alexander, I. and Estache, A. (2000). Infrastructure restructuring and regulation: Building a base for sustainable growth, World Bank.

Akintoye, A. and Renukappa, S. (2013). 4. The UK water industry: infrastructure, governance and. Water Governance: An Evaluation of Alternative Architectures, 81.

Argyris, C. (1960). Understanding organizational behavior.

Argyris, C. and Schon, D. A. (1974). Theory in practice: Increasing professional effectiveness. Jossey-Bass.

Balogun, J. and Hope Hailey, V. (2004). Exploring Strategic Change, 2nd Edn (London: Prentice Hall).

Barro, Robert J., (1990). Government Spending in a Simple Model of Endogenous Growth, Scholarly Articles 3451296, Harvard University Department of Economics.

Bernard, H. R. (2011). Research methods in anthropology. Rowman Altamira.

Bissell, J. J. (2010). Resilience of UK infrastructure. Post note., (362), 1-4.

Bryman, A. Eds. (1988). Doing research in organizations, London Routledge. 34-52.

Burnes, B. (1996). No such thing as... a "one best way" to manage organisational change. Management Decision, 34(10), 11-18.

Burnes, B. (2004). Managing change: A strategic approach to organisational dynamics. Pearson Education.

Cabinet Office (2011). National Construction Strategy 2011.

Checkland, P. (1989). Soft systems methodology. Human Systems Management, 8(4), 273-289.

Coghlan, D. and Brannick, T. (2005). Doing Action Research in Your Own Organisation. 2nd ed, London, Sage. 
Crafts, N. (2009). Transport infrastructure investment: implications for growth and productivity. Oxford Review of Economic Policy, 25(3), 327-343.

Crespin-Mazet, F. and Portier, P. (2010). The reluctance of construction purchasers towards project partnering. Journal of Purchasing and Supply Management, 16, 230-238.

Daellenbach, H. G. (2001). Hard OR, soft OR, problem structuring methods, critical systems thinking: a primer. In Proceedings of the ORSNZ Conference Twenty Naught One, University of Canterbury, Christchurch, New Zealand. Routledge.

Denscombe, M. (2010). The good research guide: for small-scale social research projects. Open University Press.

DeWalt, K. M. and DeWalt, B. R. (2010). Participant observation: A guide for fieldworkers. Rowman Altamira.

Eberhard, A. (2007). Infrastructure regulation in developing countries: an exploration of hybrid and transitional models. Public-Private Infrastructure Advisory Facility, World Bank, Working Paper.

EC Harris (2013). Global infrastructure Investment index: Move from risk to reward.

Égert, B., Kozluk, T., and Sutherland, D. (2009). Infrastructure and growth: empirical evidence (No. 2700). CESIFO working paper.

Fawcett, S. E., Magnan, G. M., and McCarter, M. W. (2008). A three-stage implementation model for supply chain collaboration. Journal of Business Logistics, 29(1), 93-112.

Ford, R. and Poret, P. (1991). Infrastructure and privatesector productivity (No. 91).

Gorman, G. E. and Clayton, P. (1997). Qualitative research for the information professional: A practical handbook, Library Association. London, England.

Gramlich, E. M. (1994). Infrastructure investment: A review essay. Journal of economic literature, 32, 1176-1196.

Hall, B. H. and Mairesse, J. (2006). Empirical studies of innovation in the knowledge-driven economy. Economics of Innovation and New Technology, 15(45), 289-299.

Hartley, J. (2004). Case Study Research. In: Cassell, C. and Symon, G. eds. Essential Guide to Qualitative Methods in Organisational Research. London: Sage Publications Ltd, pp. 323-333.

Hillebrandt, P. M. (1985). Economic theory and the construction industry (pp. 12-19). London: Macmillan.

HM Government (2011). Government Construction Strategy, Report by the Cabinet Office.

HM Government (2013). Construction 2025: Industrial Strategy for Construction - Government and Industry in Partnership, Report by BIS.

Infrastructure UK (2011). National Infrastructure Plan 2011. HM Treasury, UK.

Infrastructure UK (2012). Smoothing investment cycles in the water sector. HM Treasury, UK.

Infrastructure UK (2013). Infrastructure procurement route map: a guide to improving delivery capability. HM Treasury, UK.

Kessides, I. N. (2005). Infrastructure privatization and regulation: Promises and perils. The World Bank research observer, 20, 81-108.

Kindon, S., Pain, R., and Kesby, M. (Eds.) (2007). Participatory action research approaches and methods: Connecting people, participation and place. Routledge.

Kotter, J. (2011). Change management vs. change leadership-what's the difference? Forbes, Harvard Business Press.

Kutsche, Paul (1998). Field ethnography: A manual for doing cultural anthropology. Upper Saddle River, NJ: Prentice Hall.

Lewin, K. (1947). 'Group decisions and social change'. In Newcomb, T.M. and Hartley, E. L. eds. Readings in Social Psychology. New York: Henry Holt.

Lewin, K. (1951). Field theory in social science: selected theoretical papers (Edited by Dorwin Cartwright.).

Mackenzie, J., Tan, P. L., Hoverman, S., and Baldwin, C. (2012). Article 2: The Value and Limitations of Participatory Action Research Methodology. Journal of Hydrology.

McNiff, J. and Whitehead, J. (2009). You and your action research project. Routledge.

OECD (2013). OECD Economic Surveys - United Kingdom, Organisation for Economic Co-operation and Development.

Ofwat (2013). Setting price controls for 2015-20 framework and approach: A consultation (The Water Services Regulation Authority).

Ottosson, S. (2003). Participation action research-: A key to improved knowledge of management. Technovation, 23(2), 87-94.

Rahman, M. A. (1993). People's self-development: perspectives on participatory action research. A journey through experience, Zed Books.

Rees, G. and French, R. (2013). Leading, managing and developing people (No. 4th). CIPD Publications.

Rousseau, D. (1995). Psychological contracts in organizations: Understanding written and unwritten agreements. Sage Publications.

Schein, E. (1999). The corporate culture survival guide. San Francisco: Jossey Bass (1999) .

Schein, E. (2008). Clinical Inquiry / Research. In Reason, P., \& Bradbury, H. (Eds.). (2013). The SAGE handbook of action research: Participative inquiry and practice. Sage.

Shani, A. B. and Pasmore, W. A. (1985). Organization inquiry: Towards a new model of the action research process. Contemporary Organization development: Current Thinking and Applications, Scott, Foresman, Glenview, IL, 438-448.

Smith, A. (1776). The Wealth of Nations. Modern Library. New York, 1937.

Spradley, J. P (1980). Participant observation. Wadsworth, Belmont, USA.

Tao, R., Liu, S., Huang, C., and Tam, C. M. (2011). Costbenefit analysis of high-speed rail link between Hong Kong and Mainland China. Journal of Engineering, Project, and Production Management, 1(1), 36-45.

Todnem, B. R. (2005). Organisational change management: A critical review. Journal of Change Management, 5, 369-380.

Treasury, H. M. (2013). Planning for economic infrastructure. National Audit Office.

Treasury, H. M. and UK, I. (2010). Infrastructure Cost Review: Technical Report. HM Treasure and Infrastructure UK, London, UK.

Whyte, W. F. E. (1991). Participatory action research. Sage Publications, Inc.

Woodward, J. (1965). Industrial Organization: Theory and Practice. Oxford, UK: Oxford. 
World Economic Forum (2012). The Global Competitiveness Report 2012-20013.

Yin, R. K. (2009). Case study research design and methods (Fourth Ed). Sage Publications.

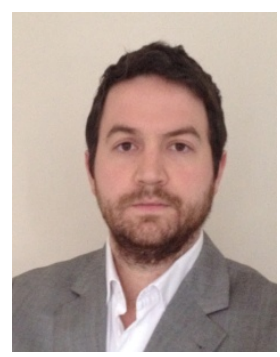

Michael Potts is undertaking his $\mathrm{PhD}$ in Infrastructure Delivery Systems in collaboration between UK WASC and the University of Salford, UK. He has since also started work within Supply Chain Management at UK WASC. He is a qualified Architect (ARB) with a Bachelors in Architecture, an MA in Architecture and Urbanism, and a Bachelor of Architecture (BArch). His interests include environmental design and management; infrastructure delivery systems; systemic delivery; organisational design and improvement; holistic cities and masterplanning; urban design and its delivery; and the interplay between policy, design, delivery and the environment.

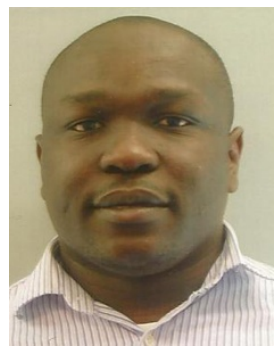

Bankole Osita Awuzie, PhD received his $\mathrm{PhD}$ in the Built Environment from the University of Salford, UK. Presently, he is a PostDoctoral Scholar at the Central University of Technology, Free State, SA. His research interests include strategic procurement; its socio-economic benefits; infrastructure and general construction delivery, both in research and practice; the sustainability agenda through Infrastructure Delivery Systems; the evaluation and (re)design of ICO Business Models; and the management and interactions between such interests within the Infrastructure Delivery System.

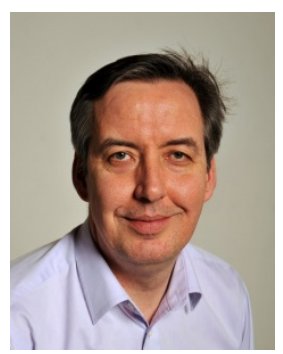

Peter McDermott is Professor of Construction Management / Procurement in the School of the Built Environment, University of Salford, UK. He holds a Bachelor's degree in Quantity Surveying, a $\mathrm{PhD}$ in Construction Management, and is a Fellow of the Institution of Civil Engineers. In addition to having led research work in the area of procurement systems, infrastructure management and social value, Peter has been applying this work with government bodies, various clients and suppliers in industry. Peter specializes in delivering social and community benefits through construction procurement.

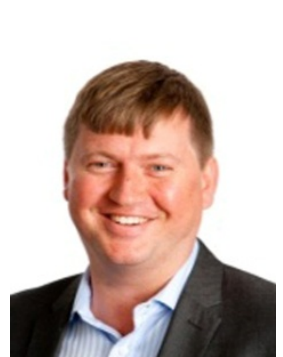

Andrew Stephenson is currently Head of Commercial for Supply Chain Management at UK WASC, he holds an MBA specializing in Construction and Real Estate, and an MSc in Construction Law and Dispute Resolution. He is a Fellow of the Royal Institute of Chartered Surveyors and the Chartered Institute of Arbitrators. His areas of specialism and interest are procurement, infrastructure, systems thinking, programme management, the built environment and organisational learning. 